\title{
PENGARUH PRODUCT PLACEMENT PADA FILM INDONESIA TERHADAP BRAND AWARENESS DAN PURCHASE INTENTION MASYARAKAT SURABAYA
}

\author{
Harris Kristanto ${ }^{1}$, Ritzky Karina M.R. Brahmana ${ }^{1}$ \\ ${ }^{1}$ Program Manajemen Pemasaran, Fakultas Ekonomi, Universitas Kristen Petra \\ Jl. Siwalankerto 121-131, Surabaya \\ E-mail: harris.christanto@yahoo.com; karina@petra.ac.id
}

\begin{abstract}
Abstrak: Product placement merupakan perkembangan strategi marketing yang tidak lagi menggunakan iklan konvensional, namun mengikuti perkembangan media komunikasi masa yang adalah media yang bergerak atau bersuara seperti radio, televisi, internet, dan media digital lainnya. Perfilman Indonesia mengalami masa keemasan hingga 30 juta penonton, dan melesatnya animo penonton tidak lepas dari kualitas film yang dihasilkan. Dapat dikatakan bahwa product placement memberikan cara-cara alternatif untuk mengekspos produknya melalui suatu medium dimana audience-nya cenderung mau untuk menerimanya, terutama di Indonesia. Tujuan dari penelitian ini adalah untuk mempelajari pengaruh product placement pada film Indonesia terhadap brand awareness dan purchase intention melalui penerapan percobaan yang dilakukan pada 100 masyarakat Surabaya. Teknik analisa yang digunakan adalah teknik analisis kuantatif dengan metode path analysis. Hasilnya menunjukan bahwa Berdasarkan hal tersebut dapat ditarik kesimpulan bahwa product placement efektif untuk meningkatkan brand awareness. Product placement juga memberikan pengaruh positif terhadap purchase intention baik secara langsung maupun melalui brand awareness.
\end{abstract}

Kata kunci: Product placement, brand awareness, purchase intention, film Indonesia, pemasaran.

\begin{abstract}
Product placement is the development of marketing strategies that are no longer using conventional advertising, but following the development of mass communication media that is moved or spoken media such as radio, television, the internet and other digital media. Indonesian film industry experienced a golden period of up to 30 million viewers, and boom interest of the audience cannot be separated from the quality of the resulting film. It can be said that product placement provide alternative ways to expose their products through a medium in which his audience tends to want to accept it, especially in Indonesia. The purpose of this research is to study the effect of product placement in movies Indonesia on brand awareness and purchase intention through the implementation of experiments conducted on 100 people in Surabaya. Analysis technique used is the technique of quantitative analysis by the method of path analysis. Based on the results show that it can be concluded that an effective product placement to increase brand awareness. Product placement is also a positive influence on purchase intention, either directly or through brand awareness.
\end{abstract}

Keywords: Product placement, Brand awareness, purchase intention, Indonesian film, marketing.

\section{PENDAHULUAN}

Menurut Panda (2004), product placement didefinisikan sebagai suatu praktek penempatan produk bermerek, kemasan atau barang merek dagang lainnya pada sebuah film, program televisi, atau media digital lainnya yang bertujuan untuk meningkatkan ingatan akan merek dan secara singkat dapat mempermudah dalam pengenalan suatu produk di suatu lokasi pembelian. Berdasarkan pengertian tersebut, dapat diinterpretasikan bahwa product placement merupakan perkembangan strategi marketing yang tidak lagi menggunakan iklan konvensional, namun mengikuti perkembangan media komunikasi masa yang adalah media yang bergerak atau bersuara seperti radio, televisi, internet, dan media digital lainnya.

Terdapat sebuah survey yang dilakukan LOWE Indonesia menunjukan bahwa sebanyak $53 \%$ pemirsa televisi di Indonesia mengganti saluran televisi ketika memasuki tayangan iklan (Tempo, 2005). Fakta tersebut menunjukan bahwa konsumen sudah banyak disuguhi iklan, dan cara ini dapat dikatakan tidak lagi efektif karena lebih dari 50\% konsumen di Indonesia tidak tertarik bahkan menghindari tayangan iklan di televisi. Oleh sebab itu diperlukan gebrakan baru strategi marketing yang lebih kreatif dan efektif dalam penggunaan media digital. Product placement dapat menjadi jawaban karena hampir pada setiap film dan program televisi menampilkan product placement, selain itu product placement dapat mengatasi zipping dan zapping (penggantian saluran) terhadap iklaniklan televisi (Van der Waldt Toit \& Redelinghuys, 2007).

Dalam pembuatan sebuah film yang mengandung product placement tentu memperhatikan ketertarikan audience dengan program yang ditayangkan baik melalui pemilihan genre maupun aktornya (Norris \& Colman, 1993). Pada tahun 2008, perfilm- 
an Indonesia mengalami masa keemasan hingga 30 juta penonton, dan melesatnya animo penonton tidak lepas dari kualitas film yang dihasilkan (Kompasiana, 2015). Dapat dikatakan bahwa product placement memberikan cara-cara alternatif untuk mengekspos produknya melalui suatu medium dimana audiencenya cenderung mau untuk menerimanya, terutama di Indonesia.

Pemutaran film dapat membuat produk-produk yang terdapat di dalamnya (product placement) dapat terlihat oleh audience atau penontonnya dalam jumlah yang cukup besar dan lebih dari sekali terjadi pengulangan, sehingga exposure yang dihasilkan akan sangat besar dan diharapkan memiliki efektifitas yang cukup besar pula dalam menimbulkan awareness akan suatu produk maupun merek (You, 2004). Hal itu berarti, product placement dalam sebuah film dapat menimbulkan brand awareness karena terdapat atensi yang tinggi terhadap suatu produk yang ditampilkan dalam film.

Product placement juga memiliki fungsi lain yang membantu sebuah film menjadi lebih nyata bagi penontonnya. Produk yang digunakan di dalam film memberikan kesan bahwa film tersebut benar terjadi dan menjadi bagian dari kehidupan penontonnya. Penonton akan lebih mempercayai dan menjadi bagian dari sebuah tayangan, apabila mereka melihat produk yang sehari-hari mereka gunakan, dibandingkan apabila karakter dalam film tersebut menggunakan produk fiktif.

Oleh karena itu, melihat fenomena ini maka diteliti pengaruh product placement pada film Indonesia terhadap brand awarenes dan purchase intention. Dalam penelitian ini, peneliti hendak mengukur pengaruhnya secara kuantitatif dengan menyebarkan kuisioner pada masyarakat Surabaya yang menonton film Indonesia.

\section{KAJIAN PUSTAKA}

\section{Product Placement}

Dalam berbagai literature yang ditulis, istilah product placement sering kali disebut juga dengan brand placement. Sehingga dalam penelitian ini penulis akan memperlakukan istilah tersebut secara sama. Product placement adalah sebuah cara untuk meningkatkan promosi sebuah produk atau jasa dengan menampilkan produknya dengan kesan bahwa keberadaan produk tersebut seolah-olah menjadi bagian dari cerita film dan acara televisi (Belch and belch, 2004: 450). Product placement digunakan untuk meningkatkan pengetahuan akan merek (brand knowledge) di antara konsumen dalam setiap media beriklan yang digunakan.
Ada tiga jenis dimensi utama yang digunakan dalam penerapan product placement atau brand. Dimensi tersebut disebut Tripartite Typology atau tiga dimensi yang membangun. Teori ini terdiri dari visual placement atau penempatan visual, auditory placement atau penempatan pendengaran, dan Plot connection atau koneksi plot (Russel, 1998).

\section{Visual Placement}

Dimensi ini terjadi ketika sebuah produk, layanan, atau logo bisa dengan sederhana diamati dalam pengaturan sebuah acara televisi atau film. Sebagai contoh, selama program televisi anda mungkin memperhatikan bahwa sekaleng Pringles ada di ats meja dapur. Efek bahwa placement telah ada pada brand attitudes konsumen tidak dapat diukur untuk hari ini, tetapi penelitian telah menunjukan bahwa jumlah tampilan product placement di layar dapat meningkatkan pengakuan atas sebuah produk. Namun, beberapa pemasar mencobamengikuti "taktik penempatan layar" karena mereka percaya bahwa itu akan meningkatkan kesadaran merek dan meningkatkan citra merek.

Kebanyakan pemasar percaya bahwa menunjukan produk berulang kali selama program dinilai tinggi karena akan meningkatkan pengakuan konsumen (Russell, 1998). Taktik ini bisa menjadi salah satu yang berbahaya karena kemunculan produk berulang-ulang selama program atau film dapat menyebabkan kecurigaan bahwa produk ditampilkan untuk alasan iklan. Produk yang disajikan hanya secara visual dan tidak dibahas tidak begitu efektif karena saluran ini hanya menampilkan produk tanpa mendiskusikan mereka (Russel, 1998). Kadang-kadang item yang hanya ditampilkan sebagai bagian dari latar belakang pemandangan akan cenderung tidak diketahui oleh pemirsa karena mereka cenderung mendengarkan dari pada mengamati bagian tersebut.

\section{Auditory Placement}

Dimensi ini terjadi ketika sebuah karakter dinyatakan secara verbal diperdengarkan dalam program ini. Pengaruh penempatan pendengaran tergantung pada tiga faktor Russel (1998):

- The context in which the brand is mentioned atau konteks penyebutan merek tersebut.

- The frequency that the brand is mentioned atau frekuensi penyebutan sebuah merek.

- The emphasis placed on the brand name atau adanya penekanan yang ditujukan pada merek tersebut

Informasi pendengaran memiliki efek yang lebih besar dari pada penempatan visual bagi pemirsa karena mereka dapat memproses informasi bahkan ketika mereka tidak melihat layar televisi atau 
film. Orang cenderung lebih memperhatikan apa yang sedang dibicarakan oleh karakter. Gisela Dawson, presiden penempatan Catalyst Group, mengklaim bahwa, "Ketika bintang menyebutkan produk yang dikenali, penonton akan memuji dirinya sendiri di belakang dan berkata," Lihat bagaimana pintarnya saya karena menggunakan hal yang sama seperti yang digunakan pahlawan saya" (Rosenberg, 2000).

\section{Plot Connection}

Dimensi placement ini paling sering dilakukan dan dapat dikatakan paling efektif karena biasanya memiliki dampak yang besar dalam mengkomunikasikan sebuah merek. Sambungan Plot terjadi ketika sebuah merek memberikan kontribusi rendah atau tingkat tinggi untuk alur cerita Russel (1998). Sebagai contoh, anggaplah bahwa pemain Will dan Grace melakukan sebuah episode yang melibatkan pembelian Honda baru untuk salah satu karakter. Merek terintegrasi ke dalam cerita karena karakter akan berhadapan dengan produk sepanjang episode. Plot koneksi biasanya melibatkan penangangan fisik produk dan dapat memiliki dampak yang besar saat pemirsa terhubung pada merek yang terhubung pada plot Russell (1998).

\section{Brand Awareness}

Menurut Aaker (1996) brand awareness adalah sebagai kemampuan dari seorang pelanggan potensial untuk mengenali atau mengingat kembali bahwa suatu merek merupakan bagian dari kategori produk tertentu.

Brand awareness membutuhkan jangkauan kontinum dari perasaan yang tidak pasti bahw merek tertentu telah dikenal sebelumnya, sehingga konsumen yakin bahwa produk tersebut merupakan satusatunya merek dalam suatu kelompok produk.

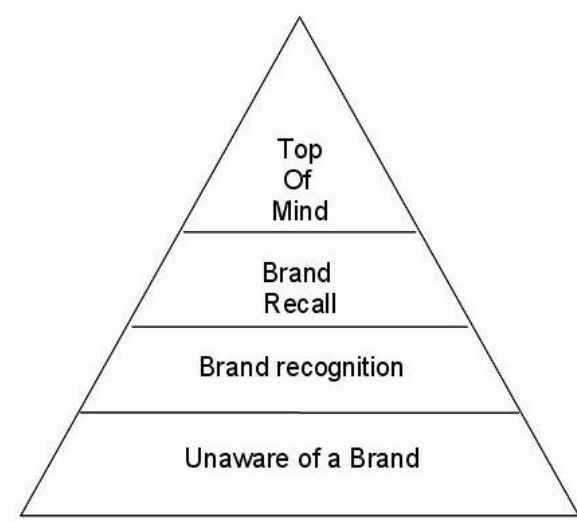

Gambar 1. Piramida Brand Awareness Sumber: Durianto, Sugiarto \& Sitinjak (2004:54-55)
Peran brand awareness dalam brand equity terantung pada tingkatan akan pencapaian kesadaran di benak konsumen. Tingkat brand awareness yang paling rendah adalah brand recognition (pengenalam merek) atau disebut juga sebagai tingkatan pengingatan kembali dengan bantuan (aided recall). Tingkatan berikutnya adalah tingkatan brand recall (pengngatan kembali merek) atau tingkatan pengingatan kembali merek tanpa bantuan (unaided recall) karena konsumen tidak perlu dibantu untuk mengingat merek. Pengukuran pengenalan merek tanpa bantuan lebih sulit dibandingkan pengenalan merek dengan bantuan. Tingkatan berikutnya adalah merek yang disebut pertama kali pada saat pengenalan merek tanpa bantuan yaitu top of minds (kesadaran puncak pikeran). Top of mind adalah branda awareness tertinggi yang merupakan pimpinan dari berbagai merek yang ada dalam pikiran konsumen.

Kemampuan pelanggan untuk mengenali atau mengingat suatu merek produk tergantung pada tingkat komunikasi atatu persepsi pelanggan terhadap merek produk yang ditawarkan. Berikut adalah tingkatan dari brand awareness Aaker (1996):

1. Unaware of brand

Pada tahapan ini, pelanggan merasa ragu atau belum yakin apakah sudah mengenali merek yang disebutkan atau belum. Pelanggan juga tidak menyadari akan kehadiran merek yang disebutkan.

2. Brand recognition

Pada tahapan ini, pelanggan mampu mengidentifikasi merek yang disebutkan. Pelanggan sudah mengenal tetapi masih membutuhkan alat (bantuan) untuk mengingat merek tersebut. Implikasi dari brand recognition ini menjadi penting ketika seseorang berada pada suatu point of purchase. Untuk meningkatkan brand recognition nama merek haruslah berbeda, khusus, dan tidak biasa.

\section{Brand recall}

Pada tahapan ini, pelanggan mampu mengingat merek tanpa diberikan stimulus. Pengingatan kembali terhadap merek didasarkan pada permintaan seseorang untuk menyebutkan merek tertentu dalam suatu kelas produk. Menurut Keller (2003) untuk meningkatkan brand recall maka nama merek yang dipilih harus:

- Nama merek sederhana dan mudah untuk diucapkan. Kesederhanaan nama merek dapat mempermudah konsumen dalam memahami nama merek.

- Kemudahaan untuk diucapkan diperlukan untuk meningkatkan pengulangan secara lisan dalam rangka membangun daya ingat yang kuat. Pengucapan juga mempengaruhi timbulnya perhatian dan keinginan konsumen menyebutkan nama merek secara lisan. 
- Idealnya nama merek harus jelas dapat dipahami dan tidak memiliki arti yang ambigu.

- Untuk mempertinggi brand recall nama merek harus terdengar akrab dan memiliki arti.

\section{Top of mind}

Pada tahapan ini, pelanggan mengingat merek sebagai yang pertama kali muncul di pikiran saat berbicara mengenai kategori produk tertentu, berada pada posisi istimewa. Dalam pengertian sederhana, merek tersebut menjadi pimpinan dalam benak konsumen tersebut dibandingkan nama merek-merek lain.

\section{Purchase Intention}

Niat adalah salah satu faktor internal yang mempengaruhi perilaku konsumen, niat adalah suatu bentuk pikiran nyata yang merupakan refleksi dari rencana konsumen untuk membeli sebuah produk atau jasa dalam periode waktu tertentu (Schiffman dan Kanuk, 2000). Niat membeli adalah keinginan Individu untuk membeli merek tertentu yang telah dipilih untuk diri mereka sendiri setelah melalui beberapa evaluasi (Laroche and Zhou, 1996). Dalam proses akan melakukan sebuah pembelian, niat membeli seorang konsumen berkaitan erat dengan motif yang dimilikinya untuk memakai ataupun membeli produk atau jasa tertentu. Motif pembelian yang dimiliki setiap konsumen berbeda-beda.

Menurut Ferdinand (2006), minat beli dapat didefinisikan melalui indikator-indikator sebagai berikut:

1. Minat transaksional, yaitu kecenderungan untuk membeli produk.

2. Minat referensial, yaitu kecenderungan seseorang untuk merefrensikan produk kepada orang lain.

3. Minat preferensial, yaitu minat yang menggambarkan perilaku seseorang yang memiliki preferensi utama pada produk tersebut. Preferensi ini hanya dapat diganti jika terjadi sesuatu dengan produ preferensinya.

4. Minat eksploratif, minat ini menggambarkan perilaku seseorang yang selalu mencari informasi mengenai produk yang diminatinya dan mencari informasi untuk mendukung sifat-sifat positif dari produk tersebut.

\section{Kerangka Konseptual dan Hipotesis Penelitian}

Model dalam penelitian ini digambarkan seperti Gambar 2.

Berdasarkan kerangka konseptual pada Gambar 2 dapat dirumuskan hipotesis penelitian sebagai berikut ini:
H1: Product placement dalam film Indonesia akan mempengaruhi brand awareness konsumen.

H2: Product placement dalam film Indonesia akan mempengaruhi purchase intention konsumen.

H3: Brand awareness dalam film Indonesia akan mempengaruhi purchase intention konsemen.

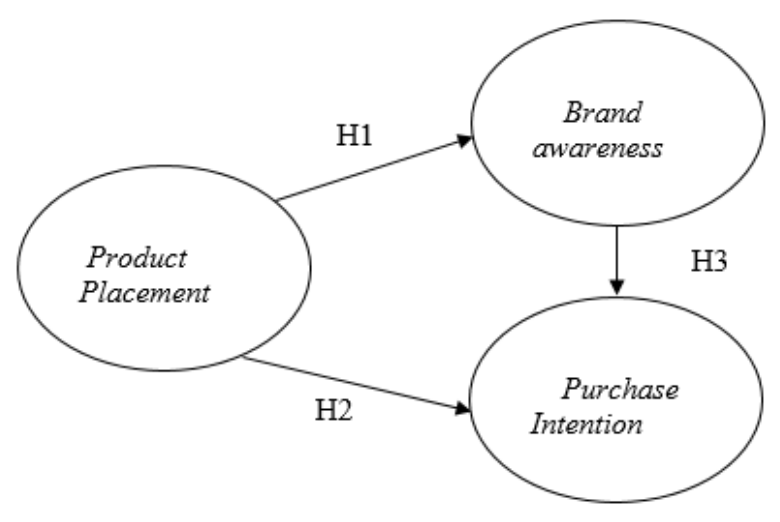

Gambar 2. Kerangka Konseptual

\section{METODE PENELITIAN}

Penelitian ini termasuk deskriptif kausal, yang bertujuan untuk menjelaskan, meringkaskan berbagai kondisi, berbagai situasi atau berbagai variabel yang timbul di masyarakat yang menjadi objek penelitian itu berdasarkan apa yang terjadi. Kemudian mengangkat ke permukaan karakter atau gambaran tentang kondisi, situasi ataupun variabel tersebut (Malhotra, 2012, p.108). Sampel penelitian ini adalah masyarakat Surabaya usia 18-35 tahun. Teknik penarikan sampel yang digunakan adalah teknik Non Probability Sampling yang mana kesempatan setiap individu untuk menjadi sampling tidak sama, bahkan ada unit populasi yang nilai probabilitasnya untuk terpilih menjadi unit sampel adalah sama dengan 0 atau 1 (Silalahi, 2003 Lebih dalam lagi, peneliti menggunakan teknik purposive sampling. Purpose sampling yaitu "pengambilan sampel berdasarkan karakteristik yang sudah ditentukan" (Silalahi, 2003, p. 74). Teknik analisis data yang digunakan dalam penelitian adalah Path analysis, Indicator Reliability dan Internal Consistency Reliability, Convergent Validity dan Discriminant Validity, Path Coefficient dan T-test.

\section{PEMBAHASAN}

\section{Convergent Validity}

Convergent validity berhubungan dengan prinsip bahwa pengukur (indikator) dari suatu konstruk seharusnya berkorelasi tinggi (Jogiyanto, 2009). Convergent validity merupakan evaluasi pertama 
pada outer model. Suatu indikator memenuhi convergent validity jika memiliki nilai outer loading $>0.5$. hasil dari validitas konvergen untuk masing-masing variable yaitu product placement, brand awareness dan purchase intention.

\section{Composite Realibility}

Evaluasi composite reliaility dipergunakan untuk melihat konsistensi keakuratan sebuah model dari indikator terhadap konstruk. Berikut adalah tabel hasil evaluasi composite reliability untuk setiap variabel penelitian.

Tabel 1. Tabel Composite Realibility

\begin{tabular}{lc}
\hline & Composite Reliability \\
\hline Brand Awareness & 0,960849 \\
Product Placement & 0,940294 \\
Purchase Intention & 0,925152 \\
\hline
\end{tabular}

Berdasarkan tabel di atas terlihat nilai composite reliability untuk semua variabel sudah memiliki nilai yang lebih besar dari 0,70. Dengan demikian di dalam variabel-variabel dalam model struktural tersebut telah memenuhi composite reliability.

\section{Pengujian nilai R-Square}

Berdasarkan pengolahan data dengan PLS, dihasilkan nilai koefisien determinasi ( $R$-square) seperti pada Tabel 2.

Tabel 2. Tabel nilai R-Square

\begin{tabular}{ll}
\hline & R Square \\
\hline Brand Awareness & 0,289600 \\
Purchase Intention & 0,649825 \\
\hline
\end{tabular}

Nilai $R$-square pada variabel brand awareness adalah sebesar 0,289 yang berarti bahwa variabel product placement mampu menjelaskan sebesar 28,9\% keragaman data brand awareness warga Surabaya atas film Indonesia. Sementara nilai $\mathrm{R}$ square pada variabel purchase intention adalah sebesar 0,649 yang berarti bahwa product placement dan brand awareness mampu menjelaskan keragaman data variabel purchase intention warga Surabaya atas film Indonesia sebesar 64,9\%.

Selain itu, untuk melihat kebaikan dari model struktural juga dapat dihitung nilai Q Square sebagai berikut:

$$
\begin{aligned}
\mathrm{Q}^{2} & =1-\{(1-0,289) \times(1-0,649\} \\
& =1-0,249=0,751
\end{aligned}
$$

Hasil perhitungan diperoleh nilai $\mathrm{Q}^{2}$ model sebesar 0,751 yang menunjukkan bahwa model struktural penelitian yang disusun dapat menjelaskan fenomena mengenai purchase intention warga Surabaya atas film Indonesia sebesar $75,1 \%$ atas adanya faktor product placement dan brand awareness di film yang bersangkutan.

\section{Uji model struktural}

Hasil analisa PLS menghasilkan koefisien inner weight untuk mengetahui signifikansi pengaruh dari masing-masing jalur seperti pada tabel 3 .

Tabel 3. Tabel inner weight

\begin{tabular}{lcc}
\hline & $\begin{array}{c}\text { Original Sample } \\
(\mathrm{O})\end{array}$ & $\begin{array}{c}\text { T Statistics } \\
(|\mathrm{O} / \mathrm{STERR}|)\end{array}$ \\
$\begin{array}{l}\text { Brand Awareness } \rightarrow \\
\text { Purchase Intention }\end{array}$ & 0,422763 & 4,616804 \\
$\begin{array}{l}\text { Product Placement } \rightarrow \\
\text { Brand Awareness }\end{array}$ & 0,53814 & 6,676857 \\
$\begin{array}{l}\text { Product Placement } \rightarrow \\
\text { Purchase Intention }\end{array}$ & 0,495580 & 5,573233 \\
\hline
\end{tabular}

Dari hasil inner weight pada tabel di atas dapat diuji hipotesis penelitian:

1. Product Placement pada film Indonesia berpengaruh terhadap Brand Awareness

Hasil inner weight untuk jalur pengaruh product placement terhadap brand awareness diperoleh nilai koefisien sebesar 0,538 dengan nilai $\mathrm{T}$ Statistics sebesar 6,676 yang lebih besar dari ketetapan 1,96. Berdasarkan hasil tersebut dapat disimpulkan bahwa product placement pada film Indonesia memiliki pengaruh yang signifikan terhadap brand awareness yang ditunjukkan oleh warga Surabaya. Pengaruh yang dihasilkan oleh product placement terhadap brand awareness adalah positif yang berarti apabila product placement pada film Indonesia semakin bagus maka brand awareness yang ditunjukkan oleh warga Surabaya juga akan semakin tinggi.

2. Product Placement pada film Indonesia berpengaruh terhadap Purchase Intention

Hasil inner weight untuk jalur pengaruh product placement terhadap purchase intention diperoleh nilai koefisien sebesar 0,496 dengan nilai $\mathrm{T}$ Statistics sebesar 5,573 yang lebih besar dari ketetapan 1,96. Berdasarkan hasil tersebut dapat disimpulkan bahwa product placement pada film Indonesia memiliki pengaruh yang signifikan terhadap purchase intention yang akan dilakukan oleh warga Surabaya. Pengaruh yang dihasilkan oleh product placement terhadap purchase intention adalah positif yang berarti apabila product placement pada film Indonesia semakin bagus maka purchase intention yang akan ditunjukkan oleh warga Surabaya juga akan semakin tinggi. 
3. Brand Awareness pada film Indonesia berpengaruh terhadap Purchase Intention

Hasil inner weight untuk jalur pengaruh brand awareness terhadap purchase intention diperoleh nilai koefisien sebesar 0,423 dengan nilai $\mathrm{T}$ Statistics sebesar 4,617 yang lebih besar dari ketetapan 1,96. Berdasarkan hasil tersebut dapat disimpulkan bahwa brand awareness pada film Indonesia memiliki pengaruh yang signifikan terhadap purchase intention yang ditunjukkan oleh warga Surabaya. Pengaruh yang dihasilkan oleh brand awareness terhadap purchase intention adalah positif yang berarti apabila brand awareness pada film Indonesia semakin bagus maka purchase intention yang ditunjukkan oleh warga Surabaya juga akan semakin tinggi.

\section{KESIMPULAN DAN SARAN}

\section{Kesimpulan}

Hasil penelitian yang dilakukan oleh peneliti membahas mengenai pengaruh product placement terhadap brand awareness dan purchase intention menghasilkan kesimpulan sebagai berikut:

1. Adanya pengaruh positif dan signifikan antara product placement pada film Indonesia terhadap brand awareness masyarakat Surabaya. Hasil inner weight untuk jalur pengaruh product placement terhadap brand awareness diperoleh nilai koefisien sebesar 0,538 dengan nilai T-statistics sebesar 6,676 yang lebih besar dari ketetapan 1,96. Berdasarkan hasil tersebut dapat ditarik kesimpulan semakin baik dari sebuah penempatan produk pada film Indonesia maka brand awareness yang ditunjukan oleh warga Surabaya juga akan semakin tinggi.

2. Pengaruh product placement terhadap purchase intention menunjukan nilai yang positif dan signifikan. Dalam hal ini ketika penonton film Indonesia dapat menyadari adanya penempatan produk pada sebuah film yang mereka tonton maka akan memberikan dampak positif terhadap purchase intention pada produk atau merek tersebut.

3. Pengaruh brand awareness terhadap purchase intention menunjukan nilai yang positif dan signifikan. Semakin baik kesadaran sebuah merek dalam hal mengenal dan mengingat akan suatu merek pada film Indonesia yang ditonton maka semakin berpengaruh positif pula pada purchase intention warga Surabaya.

Berdasarkan hal tersebut dapat ditarik kesimpulan bahwa product placement efektif untuk mening- katkan brand awareness. Product placement juga memberikan pengaruh positif terhadap purchase intention baik secara langsung maupun melalui brand awareness.

\section{Saran}

Penggunaan product placement pada film Indonesia semakin berkembang. Bagi produsen tentunya hal ini adalah sebuah peluang. Berdasarkan kesimpulan dari hasil penelitian ini, beberapa saran yang dapat diajukan adalah:

1. Untuk meningkatkan niat membeli maka sponsor dari product placement harus sesuai dengan jenis film dan juga target penonton dari film tersebut.

2. Strategi penggunaan product placement yang dilakukan sebaiknya berupa placement eksplisit yang menunjukan kelebihan dari produk.

3. Penggunaan product placement harus tetap dibarengi dengan jenis promosi lainnya. Hal ini dilakukan untuk terus meningkatkan awareness konsumen terhadap produk dan juga untuk mengajak konsumen membeli produk tersebut.

Penelitian mendatang mengenai product placement di Indonesia sebaiknya memilih model, produk, media dan juga populasi yang saling sesuai untuk memberikan hasil yang lebih baik. Penelitian mendatang juga diharapkan bisa memberikan sebuah perbandingan antar produk atau antar media yang menggunakan product placement.

Pada penelitian mendatang, peneliti dapat mencari tau hubungan antara product placement dengan brand ambassador untuk mengetahui sejauh mana efektifitas dari sebuah product placement.

Praktisi yang menggunakan product placement sebaiknya juga menggunakan sarana promosi lain yang bisa mendukung sarana promosi lain yang mendukung efektifitas product placement, terutama untuk meningkatkan niat membeli.

\section{DAFTAR PUSTAKA}

Belch, G.E., \& Belch, M.E. (2004). Advertising and Promotion. New York: McGraw-Hill, Inc.

David, A.A. (1996). Manajemen Equitas Merek. Jakarta: Spectrum Mitra Utama.

Durianto, D., Sugiarto, \& Sitinjak, T. 2004. Strategi menaklukan Pasar Melalui Riset Ekuitas dan Perilaku Merek. Jakarta: PT. Gramedia Pustaka Utama.

Ferdinand. (2006). Pengembangan Minat Beli Merek Ekstensi. Badan Penerbit Universitas Diponegoro. Semarang. 
Jogiyanto, HM. (2009). Analisis dan Desain. Yogyakarta: Andi OFFSET.

Keller, K.L. (2003). Strategic Brand Management, Building, Measuring, and Managing Brand Equity ( $2^{\text {nd }}$ ed). USA: Prentice Hall.

Khairunnisa. (2005). 53 Persen Pemirsa Nilai Iklan Televisi Membosankan; http://www.tempo.co/ $\mathrm{read} / \mathrm{news} / 2005 / 03 / 03 / 05657418 / 53$-PersenPemirsa-Nilai-Iklan-Televisi-Membosankan (akses 11 Maret 2015).

Laroche, M., Kim, C. and Zhou, L. (1996). 'Brand familiarity and confidence as determinants of purchase intention: an empirical test in a multiple brand context', Journal of Business Research, 37(2), 115-120.

Malhotra, N.K. (2012). Basic Marketing Research $\left(4^{\text {th }}\right.$ ed). New Jersey: Pearson Education. Inc.

Norris, C.E., \& Colman, A.M. (1993). Context Effects on Memory for Television Advertisements. Social Behavior and Personality, 21(4), 279-296.

Panda, T.P. (2004). Effectiveness of Product Placements in Indian Films and Its Effects on Brand Memory and Attitude with Special Reference to Hindi Films. Jurnal of Indian Institute of Management Kozhikode.
Rosenberg, M.K. (2000). The e-learning Readiness Survey. Retreived 5 April, 2015, from: http://www.ucalgary.ca/srmccaus/eLearning_Su rvey.pdf.

Russel, C.A. (1998). Toward a Framework of Product Placement: Theoretical Propositions, in Advances in Consumer Research, vol. 25, Joseph W. Alba and J Wesley Hutchinson, eds., Provo, UT: Association for Consumer Research, 357-362.

Silalahi U. (2003). Studi Tentang Ilmu Administrasi. Bandung: Sinar Baru Aglesindo.

Schiffman, L.G., \& Kanuk, L.L. (2000). Consumer Behavior. $7^{\text {th }}$ ed. New Jersey: Prentice Hall.

Van der Walt, DLR \& Du Toit, Redelinghuys, R. (2007). Does Branded Product Placement in Film Enhance Realism and Product Recognition by Consumers? African Journal of Business Management pp.019-025.

You, I. (2004). Product Placement Belief and Product Usage Behavior in South Korea and the United States. Thesis Master in University of Florida.

Kompasiana (23/03/2015). Meningkatkan Kualitas Film, Mengatrol Jumlah Penonton. Retreived 2015. 